\title{
Lembranzas de infancia na escola de Meilide
}

Non pretendo contar nin unha historia grande, e polo miúdo dos miúdos, nin tampouco unha historia especialmente significativa. Quero simplemente lembrar, evocar, facer unha reconstrución minimalista dunha pequena escola do rural galego na posguerra. Trátase de renderlles homenaxe a aquelas xentes nosas que tiveron que vivir e sufrir una experiencia singularmente dura e difícil, con dúas únicas posibilidades: a miseria ou a emigración.

Escribir sobre a infancia é como volver vivir. É máis que unha lembranza. É revivir, sentir de novo na distancia, máis aló do tempo, fóra xa do lugar. Escribir sobre a infancia é, ás veces, pura nostalxia, dor punxente do tempo pasado, escuro presentimento, intento de reconstruír a pequena historia de cada un.

Nos últimos tempos téñense feito cousas fermosísimas sobre a historia da infancia. Aquí, na nosa coidada biblioteca da USC, temos algúns primores, dende as obras clásicas de De Mause ou Philippe Ariès até libros de título tan suxestivo como Être enfant à Rome ou L'enfant à l'ombre des cathédrales. Cómpre recordar, por exemplo, respecto á atención e aos coidados pola historia da infancia, esa exquisitez literaria que son as Memorias dun neno labrego de Xosé Neira Vilas. Relato paradigmático da vida dun rapaz no rural galego a mediados do século XX. Contribución decisiva para a caracterización da historia contemporánea da infancia en Galicia, que arranca da obra plástica e narrativa de Castelao, dos seus debuxos de nenos. Caricaturas antolóxicas e definidoras dos nosos rapaces e, por tanto, de nós mesmos.

\section{Recordo incesante}

Sempre levarei comigo no fío da memoria a lembranza da miña escola. Experiencia intensa e verdadeira sempre. Experiencia con certa carga dramática... No meu caso, 0 drama estaba no contorno. $O$ drama acababa de pasar e estaba pasando.

Debía ter eu tres anos —outubro de 1940 - cando cheguei a Meilide, unha aldeíña de Cerdedo, en Terra de Montes, entre Pontevedra e Ourense. Alá cheguei, como nun soño, unha noite de choiva, vento e tronos. Unha desas noites negras e case infindas do noso inverno. Un pouco andando, outro pouco nos brazos da miña nai, pero, sobre todo, ás cabaliñas dalgún rexo veciño da aldea que nos viñera agardar a Cerdedo para indicarnos o camiño. Un camiño sen luces, tenebroso e neboento, os camiños e as corredoiras da nosa terra... que ían alumando aqueles candís que como pequenos fachos da Santa Compaña levaban os nosos acompañantes.

Aínda teño gravado o son algareiro da auga que corría polas beiras dos camiños e a ben máis barullenta e emocionante do río Piñoa ao atravesar a ponte entre Cerdedo e 
Meilide. Aquela ponte chea de engado dende a que, moitas veces e durante anos, puiden ver as troitas relucentes de cores, entre os remuíños dunha auga cristalina que baixaba precipitadamente dende 0 alto daqueles montes.

Esa debe ser unha das vivencias infantís máis intensas das que eu teño recordo. Unha vivencia que me acompañaría toda a vida e en todas as partes. Unha emoción e un tremor que me faría vibrar sempre con case todas as formas extremas de manifestación da natureza: o vento tempestuoso e zoante, a choiva escura e torrencial inacabable, os lóstregos e a tronada horrísona, a noite fecha.

Pero vaiamos á escola... unha pequena escola de aldea que pode resumir a conciencia educativa dunha época e o peso decisivo do rural na historia máis recente de Galicia... que parece que se acaba, pero que se quere salvar. De onde saían as escolas rurais unitarias daquel tempo? Saían da desfeita da guerra civil. Da morte por fusilamento da vibrante escola republicana. Saían da emigración forzosa do campo á cidade ou do traballo temporal Ionxe da casa. Saían da pobreza e da fame en non poucos casos. E aquela escola unitaria rural de Meilide, en Cerdedo, típica de posguerra, foi a miña escola entre 1940 e 1946. Xa sei que Antonio Molero, Agustín Escolano, Antonio Viñao e outros colegas teñen estudado ben ese tipo de escola xalundes. E mesmo que a seguen a estudar. Pero esta experiencia persoal propia é quizais a mellor maneira que eu teño para dar a coñecer por dentro a escola rural galega daquel tempo. Neste intento de tirar conclusións histórico-educativas ou histórico-pedagóxicas dun caso singular, é imprescindible o testemuño persoal.

\section{Eu nacín á vida naquela escola}

Son as servidumes de ser fillo de mestres... A miña primeira e máis afastada memoria persoal comeza naquela casa-escola da montaña galega, nun segundo andar e sobre un almacén repleto de aveños e ferramentas dos oficios. Un único cuarto con retrete, nun extremo da casa, e no outro a cociña, cun balcón que miraba cara a unha encrucillada de camiños e cara a unha fonte que estaba un pouco máis aló. E no medio e medio, o templo escolar: unha sucesión de mesas e bancos fixos, un corredor central, tres ventás dun lado e unha do outro, a mesa da mestra, un reloxo, os mapas, o gran encerado e os retratos de Franco e a Purísima Concepción... E a bandeira vermella e amarela un pouco apartada...

Lémbrome ben. Nada máis erguerme da cama, atravesaba correndo a escola para ir á cociña tomar o almorzo: leite de vaca fresco con pan de millo e un pouco de azucre. Toda a miña vida ficaría xa engaiolado polo leite como alimento; nunca me cansei del. Saía coma un lóstrego á rúa para xogar coas miñas compañeiras e cos meus compañeiros, que me agardaban nos campos próximos. Alí non había estradas, nin coches, nin luz eléctrica. Só había candís, velas e luz de carburo o día da festa ou dalgún convite.

Escola marabillosamente mixta forzada pola necesidade, pola pobreza e polas circunstancias. Coeducación auténtica, pletórica e espontánea. Convivencia de nenos e nenas dentro e fóra da escola. Pero seguramente tamén - teño algunhas lembranzas diso- a presenza dun machismo moitas veces brutal que dominaba todas as relacións entre nenos e nenas. 
Despois, subiamos todos xuntos armando un gran balbordo cos duros e resistentes zocos con chatolas, petando con forza nas escaleiras de madeira. Comezaba así a sesión da mañá. Pero non para min! Aínda tiña catro ou cinco anos e non estaba en idade escolar, por moito que a escola estivese na miña casa. A verdade é que quedaba alí enredando un pouco, xogando como que escribía ao ditado, paseando por todas as partes. Un mal exemplo de fillo da mestra. Parece que non tiña présa por aprender a ler. Os estímulos e o ambiente levábanme por outro lado. Prefería o campo, a liberdade, os xogos ao aire libre, ir coas xentes que me levaban ás leiras, chamar as vacas, tornar a auga nos distintos campos e campelos, apañar cereixas, amorodos ou patacas, correr polas corredoiras, escoitar os paxaros ou coller bolboretas.

Parada para comer —na cociña da casa-escola ou na casa dalgún veciño-e volta a empezar. As comidas en casas alleas. Que privilexio ser o fillo da mestra! Canta emoción me suscita aínda o recordo intenso do caldo renovado, dese particular doce de entroido que era a bica —ou bincha, como dicían alí-, das castañas asadas na lareira ou do fígado con patacas e as filloas de sangue o día da matanza. E, que espectáculo o da matanza! Que partidos de fútbol coa vexiga do porco ben inflada que tanto axudaba a limpar os zocos!

\section{Os xogos}

Nos meus anos que poderiamos chamar preescolares, agardaba fóra da escola o final da sesión da tarde dos meus compañeiros e compañeiras e comezaban os xogos no monte, no val ou xunto ao río Piñoa, un afluente do Lérez, co que se xunta alí mesmo en Cerdedo e onde, por certo, merendaban de cando en vez Graham Greene e Leopoldo Durán, o crego especialista na literatura e no ensarillado mundo relixioso do autor de $O$ poder e a gloria ou $O$ factor humano. Xogos longos, infinitos, con esa asombrosa flexibilidade do tempo infantil. Xogos máxicos permanentemente recordados.

Xogabamos ás vacas, ás carreiras, a esvarar polas ladeiras das laxes sentados sobre pedras planas. Xogabamos aos niños - coma paxaros en liberdade-, imitando o seu canto; aos cregos, arremedando casoiros e tratando moi a miúdo de reproducir cerimonias sexuais iniciáticas con todo realismo, pola observación inevitable da vida dos animais, tan cerca das persoas, tan próximos sempre, tan "humanizados"...

O campo e o aire libre eran unha beizón. Eran a nosa verdadeira liberación. Afirmación de vida, fronte á represión institucionalizada. Así, por San Martiño, trompos ao camiño. En Dorrón e Raxó, pouco tempo despois, cos trompos e coas subelas, xogabamos ao rodo (un gran círculo riscado en terra chá) e aos anicazos - aos anicasos, dicíase alí polo seseo-.

O xogo da billarda —o vai, como lle chamaban en Cambados - tan espectacular e variado, con tantísima historia, un xogo practicamente medieval. A primavera era a época do risco, unha variante da rayuela de Cortázar, que se debuxaba na terra, riscando - de aí o seu nome-, ou ben na propia vía pública, pintado cun anaco de tella ou algo parecido. Xogo de precisión e fantasía, de tento e cálculo. O xogo da corda ou comba, tan socorrido, 
tan atlético, tan ximnástico, tan mixto e coeducativo, pero, daquela, máis propio das rapazas. Elas eran auténticas virtuosas e podían sempre con nós.

As bólas, unha paixón. Potencia e precisión dixital, con caída da unlla do dedo gordo moitas veces. $O$ guá tan celebrado. Xogos magníficos todos, que non cito agora por extenso, porque xa están ben recollidos nos estudos do Xocas e doutros investigadores.

\section{Os escolinos}

Así lles chaman no Courel aos alumnos da escola infantil e primaria: escolinos. Debeu ser máis ben aos sete que aos seis anos cando chegou o momento de que sentase con máis seriedade naqueles bancos escolares, nos que estabamos de dous en dous. Homes nunha ringleira e mulleres noutra. Nenos con nenos e nenas con nenas, pero preto uns dos outros. Eramos entre 40 e 50. Os máis pequenos, sentados en bancos corridos, nos laterais das paredes da escola. E os maiores -ou os que sabían máis-, nos bancos centrais, por parellas.

Pero, quen eran aqueles escolinos da posguerra e da montaña galega? Quen eran aqueles rapaces da Galicia triste y pura como la lluvia, salada para siempre por las lágrimas, como dixera un día Pablo Neruda - como mo recordaría anos despois en Madrid, entre chato e chato polos bares de Argüelles, o meu querido amigo e profesor Santiago Montero Díaz?

Aqueles escolinos agarimosos que ficarán para sempre na miña memoria, eran fillos de labregos na súa inmensa maioría. De labregos e tamén de traballadores dos oficios - carpinteiros, ferreiros...-. De nais labregas e de pais emigrados. Salvo contadas excepcións, gobernaban alí, a partes iguais, a pobreza e a emigración...

Era, por tanto, aquela, unha escola que loitaba e pelexaba, contra vento e marea, por alfabetizar aquel contexto socioeconomicamente deprimido, politicamente derrotado por unha guerra civil criminal e culturalmente humillado pola persecución sistemática da lingua propia, da lingua galega. Isto é, un contexto desculturizado e profundamente desmoralizado. A pelexa era, pois, contra todo e contra todos -incluídos os inspectores e inspectoras do franquismo-. Unha tarefa imposible? Pois digamos que case raiaba o imposible...

Así era o ambiente social daquela escola de Meilide. Os escolinos aprendían. Si que aprendían. Aprendían a aprender. E aprenderon con miras de futuro. Souberon investir en educación e converter todo o seu traballo en cualificación e revalorización. Algúns, mesmo conseguiron saír da pobreza. Aínda que á maior parte non lle quedou máis remedio que emigrar. Ás veces, para ben. Outras -as máis-, para mal. Sobre pobreza, emigración. E sobre emigración, fracaso...

Estabamos sentados por idades e graos, manexando aquelas vellas ou vellísimas enciclopedias - grao elemental, grao medio e, en contadísimos casos, grao superior-. Pero a maioría da clase non pasaba do coñecido Rayas ou quedaba nas Lecciones de cosas. Agora vexo todo aquilo como unha especie de reencarnación xa dexenerada e, sobre 
todo, convertida en pura retórica, do célebre slogan comeniano: texto único, método único e mestre único.

Ese slogan de Jon Amós Comenio estaba metodoloxicamente vivo, pero perdera 0 sentido do momento histórico no que nacera. 0 mundo xa era outra cousa, é certo. Pero na España da posguerra —e aínda máis en Galicia — dérase de novo un salto atrás. Toda a modernización gañada coa República, perdíase día a día. Era un retorno material ao antigo réxime e ao tardofeudalismo, que caeran de facto no período republicano - polo menos, na conciencia social da xente, dábanse por liquidados-. Pero, malia todo -e como moi ben sabemos-, aquela vida nova chea de pulo e de creatividade dos anos 30 seguía correndo coma un río soterrado e impetuoso...

Na escola de Meilide, Comenio seguía ritualmente vivo nas enciclopedias. Impúñase 0 texto único co que el soñara para unificar, recoller e resumir o saber último da súa época e contrarrestar así os erros e supersticións medievais con base no racionalismo máis estrito e cartesiano. El, un crego protestante! dubidando de todo para demostralo todo, como quería Descartes.

E ese racionalismo sistemático era o alicerce do seu método único. E para impoñelo a figura do mestre ou da mestra. Velaí o mestre único do que el nos fala. O mestre como guía e como modelo. $\mathrm{O}$ mestre ou a mestra como referentes. Pero onde quizais estivese máis vivo e fose máis actual o pedagogo checo sería nas ilustracións das leccións de cousas - "As cousas e non as palabras, que son a sombra das cousas", dicía- e nos mapas. Recordemos as súas ilustracións marabillosas do seu Orbis pictus, o mundo ilustrado!, o cómic por excelencia do seu tempo, o mundo das cores na escola, a ledicia das cousas, aínda que sexan pintadas...

Ás veces, naquela escola miña, os maiores tomábanlles a lección aos máis pequenos —primeiros soletreos, primeiros balbucidos da escolaridade tradicional-, arremedando así, nun apretado labor e case espontaneamente, os métodos do sistema monitorial. Escenificando, en definitiva, en pequena escala, os procedementos das escolas mutuas de Bell e Lancaster. Unha repetición da experiencia da escola da revolución industrial —nas grandes urbes e en grandes espazos - mais, esta vez, no rural...

Así pois, na escola de Meilide, en Cerdedo, actividade, rebulicio, tensión... Lectura en voz alta, case sempre; e mesmo, ás veces, lectura a puro berro. Lectura rítmica e compasada, de dous en dous. Exercicio permanente de declamación e memorización. Mirando o libro e sen mirar o libro. Lendo e cantando como beben e cantan as galiñas. Mestura de traballo físico e intelectual, de xogo e traballo.

E como se facía o que poderiamos chamar división do traballo na escola? Volvía saír Comenio ao escenario. Máis de trescentos anos despois da súa existencia, o horario matutino na pequena escola de Meilide, era a mellor homenaxe ao pedagogo checo: os luns, Gramática; os martes, Aritmética; os mércores, Historia Natural; os xoves, Xeografía; os venres, Xeometría; e os sábados — tiñamos libres os xoves pola tarde- Historia Sagrada. 
E despois de dar a lección, a táboa! A táboa de multiplicar. Cantabamos a táboa. Seguiamos a cantar. Como se ve, non hai nada coma o canto para calquera forma de aprendizaxe infantil. E cantabamos todos os números. Pero sentiamos predilección polos máis fáciles. Sobre todo, polo 2 e polo 5. Que ben nos saían! Que rítmicos eran 02 e 05 ! Que fáciles! En ocasións, os cánticos ían acompañados de percusión (petando nas mesas ou no chan). Cantas evocacións literarias se teñen feito co cantar infantil das escolas!...

E o mapa!... Saír ao mapa en grupo e cantar (outra vez cantar!), agora en voz baixiña, a xeografía física da Península lbérica: os límites, os montes, os ríos, as provincias... Cunha vara que era coma un vimbio -ás veces faciamos buratos no mapa, todo hai que dicilo-e en grupos pequenos: España limita al Norte con el mar Cantábrico y los montes Pirineos que la separan de Francia. Efectivamente, en poucos momentos da historia estivemos tan afastados de Francia coma neses anos de posguerra. Cantabamos con moita forza e a demasiada velocidade. Miña nai pedíanos que fósemos máis amodo.

Os montes... Os montes e os seus picachos: O Aneto, O Mulhacén, O Teide. Pero non facía falta ir tan lonxe. Alí mesmo, na Galgareta ou no Castro, en pleno corazón da Terra de Montes podíase ver a neve no inverno, sentir o canto dos carros subindo o vello camiño da montaña e mollando o eixe na fervenza de Covaladróns, escoitar pola noite o ouvear dos lobos. Aquilo si que era emocionante!

Os ríos. O mellor, o Miño, o noso, o pai Miño, que nacía daquela en Fomiñá, pero hoxe —os nosos xeógrafos xa o determinaron hai tempo, como nos conta Estro Montaña no seu fermosísimo libro Polos vieiros do vello Miño- arranca xa do Pedregal de Irimia, no alto da Serra de Meira. A auga clara e silandeira que abrolla en Fomiñá é tan plena e cristalina, tan rotunda, tan fonda, que alí deben estar sen dúbida os máis ricos mananciais que fan do Miño o rei dos nosos ríos.

E, naquel cantar imparable, as provincias!: Extremadura dos, Cáceres y Badajoz. Badaxoz! A cidade dunha das grandes masacres do exército fascista de Franco na guerra civil. A cidade do "ceo tan alto" de Castelao no desterro... Galicia, catro: Coruña, Lugo, Orense y Pontevedra, diciamos nós naquela escola tan ferreamente españolizada. Anos despois, cos meus amigos de Brais Pinto en Madrid, cantabamos aquilo de "Viva Coruña, viva Lugo, viva Ourense e Pontevedra, viva a nosa nai Galicia, viva sempre a nosa terra". Patiño metíalle moita marcha á canción e dáballe unha énfase inconfundible.

Pero para vehemencia a daqueloutra que dicía: "Ai, Armórica, Cornubria e Cambriá, Escocia, Eirín, Galicia e mais a Illa de Man; son as sete nacións celtas, fillas do pai Breogán; para ti, miña terra, nos beizos un cantar, nos peitos a ledicia da nosa mocedá". A Reimundo Patiño gustáballe introducir unha variante: despois de Galicia, engadía Valonia e falaba entón das "oito nacións celtas". No ano 2006, o "ano da memoria histórica", nunha homenaxe a Ramón Valenzuela, o sempre recordado amigo e compañeiro, nas súas terras do Deza, cantou esta canción con moito garbo, como unha canción dos seus tempos, Avelino Pousa Antelo, 92 anos! 
A verdade é que aquela escola era todo un espectáculo... Era, a un tempo, teatro e aprendizaxe. Aprendizaxe coral, colectiva, solidaria. Non había sitio para a individualización e menos para a aprendizaxe solitaria. Porque eramos moitos e estabamos moi apretados. Corpo con corpo, mente con mente. Mirar e mirarse nos outros. Sentir e apalpar ás veces o meco e o coidado posto polas casas da aldea nas roupas e nos peiteados dos seus pequechos e as súas pequechas. Pero sentir e apalpar moi a miúdo a miseria e as necesidades máis elementais dos meus amiguiños e as miñas amiguiñas. Alá ficaron, colgados no tempo a miña queridísima Maruxiña, as miñas admiradas Carmiña, María, Élida, Xuliña. Alá quedou Pepiño. E alá quedaron Xerardo, Luis, Xosé, Monsito e tantos e tantos outros.

Porque aquela escola non era só unha escola do rural. Era o rural no tempo terrible da represión e da posguerra! Terror sobre miseria. Miseria sobre humillación. Tempos aqueles de tanto desasosego que eu aínda tremo lembrando as caras de pavor das xentes en moitas situacións vividas.

Lembro un día no autobús. Aqueles autobuses con gasóxeno e de marcha lentísima que nos levaban de Pontevedra a Cerdedo, parando nun descampado fronte aos fusís da garda civil, en busca de guerrilleiros. No medio da néboa. Case de noite. Recordo hoxe aquela escena como se fose unha imaxe de guerra das moitísimas películas bélicas que vería anos despois.

\section{As tardes}

Ai, as tardes mornas e lentas da escola de Meilide! Aquelas lecturas en roda das andanzas de don Quixote e Sancho Panza! Que aventura a de ler entre todos aquelas andanzas! Había os típicos tropezos, os erros. Quen se trabucaba, quen lía con graza. Perdiámonos ás veces, pero estabamos sempre atentos para saber cando lle tocaba a cada un... E dona Concha, mudando a orde na lectura para cacharnos nas patacas.

O catecismo inefable. O catecismo do P. Astete. O "Pastete" como lle chamaba algún. Por la señal de la santa cruz, dicía eu: pero que quererá dicir porla?... Como se fose unha palabra soa... Que abstraccións! Que cousas tan abstrusas!... En las entrañas de la Virgen María... O misterio da Encarnación, ou o misterio da Santísima Trindade.

Tardes de inverno na escola, coa neve fóra. Pero tardes de abril e maio, dando clase no campo, á sombra dunha vella e inmensa cerdeira. Aquela árbore era unha metáfora da árbore da que falaba Manuel Bartolomé Cossío citando a Rousseau: el mejor lugar para una escuela es la sombra de un árbol...

Lavando aqueles marabillosos encerados de man na fonte ou afiando o lapis de lousa nunha pedra de seixo. Momentos únicos nos que si era posible evadirse do contorno e a presión ambiental sempre presente - en Galicia os nenos empezan a ser explotados nada máis botar a andar, conta en ¡Basta!, nas súas memorias, Enrique Líster- e soñar na soidade do campo, á sombra dunha cerdeira, en primavera. Ten razón Cossío. Porque alí está 0 aire, alí está a auga e alí está toda a luz... 
E de Meilide, a Dorrón, nas vacacións. Outra vez o mar. O mar que eu esquecía na montaña. Os amigos olvidados. Os avós. A casa. A outra casa... Algún daqueles anos, por un tempiño, fiquei aló, en Dorrón, durante o curso escolar. Xa sabía ler bastante ben -acórdome- - E fun á escola. Con medo, pero fun á escola. A outra escola. Con ese nó no estómago, que xa non se nos quita nunca, pero fun á escola. $E$ tiña razón en ir con medo! Verdadeiramente, aquela escola metía medo...

Coido que eramos máis de sesenta. Non era pequeno o local. Pero o mestre, ai!, aquel mestre infame era criminal. Zorregaba unhas labazadas bestiais, zapateando os nenos contra o chan —non había nenas-. Era o terror! Vin a moitos dos meus amigos e compañeiros sangrando polas orellas —as fatídicas frieiras - ou polo nariz. Eu íame librando. Sabía que estaba protexido pola relación que a miña familia tiña con el. Pero, aínda así, tremía... Un espanto.

Quédome coa memoria da miña escola de Meilide. Talvez teñamos que recuperar materialmente un día aqueles vellos camiños do auténtico. Quizabes teñamos que recuperar aquelas alamedas que nos situaban deseguido en harmonía plena coa natureza. Eu recordareinas sempre así: como alamedas da miña vida infantil, como avenidas dos meus soños, como sendas do paraíso. Debe ser certo. Aquela pequena unitaria estaba situada no centro mesmo dunha encrucillada da que, probablemente, xa non sairei nunca máis.

(Publicado na Revista Galega do Ensino, núm. 50, 2007, páxs. 56-62.) 